\title{
Managing Collaborative Education: How to Detect the Conditions of Interpersonal Disturbance of College Students from Poor Families?
}

\author{
Fenghua Liu ${ }^{1}$ Guosheng Han ${ }^{2}$ Wei-Ta Fang,"* \\ ${ }^{1}$ Students Affairs Office, Shandong University, Weihai \\ ${ }^{2}$ School of Business, Shandong University, Weihai \\ ${ }^{3}$ Graduate Institute of Environmental Education, National Taiwan Normal University, \\ Taipei (*corresponding author)
}

\begin{abstract}
The relationships between mental symptoms of low spirits from college students are seldom studied. This study has tried to understand their mental state while suffering poor environment. 581 College students were detected from random samplings in 2012. This survey has been studied their interpersonal disturbance from the Diagnostic Scale of Interpersonal Relationship (DSIR) between two universities in Shandong Province. This result shows that the total detection rate of the college students' interpersonal disturbance was shown as $39.9 \%$, among them $30.6 \%$ of which were distressed by interpersonal disturbance, and $9.3 \%$ of which were suffering seriously. However, the final results were detected significant differences on their interpersonal relationships depended on their gender, family properties, and social status.
\end{abstract}

Keywords: counseling, education science, the Diagnostic Scale of Interpersonal Relationship, psychology

\section{Introduction}

Interpersonal contact refers to a process in which through contacting in a certain way that people can affect each other' behavior and psychology. For college students, having a good interpersonal relationship is both leading as an indispensable condition and serving as an important way to their mental health [1-3]. The larger human's interpersonal space occurs, the richer their spiritual life could be. Furthermore, the more opportunities they could possibly have to get someone's help and support, the better life they would be supported from keeping their psychological balances [4-7]. On the contrary, if humans' communicative needs cannot be satisfied, they would be detected mental symptom of low spirits from their mental state which may cause psychological imbalance and even suffer physical and mental illnesses.

In the long-term teaching practice of mental health and environmental education in colleges, we have found that the interpersonal relationships have become one of the major psychological distress problems for college students. For those students from poor families, they have been determined dramatically to suffer inferior in lack of self-confidence than other students because of their poorness due to family properties and social status. This might be led themselves to be afraid of contacting with others, beyond inte- 
racting with other people. If thing goes on like this, these students would be more unsociable and lonely. The final result is not what we would like to see in our societies, like anti-social synonymous symptom, etc. Therefore, this survey was conducted with new concepts of psychological, healthy, and environmental education to detect further understandings of their interpersonal relationships of college students from poor families.

\section{Methods}

The questionnaire was divided into two parts, the first part was used to learn basic information of the respondents, and the second part is used the Diagnostic Scale of Interpersonal Relationship (DSIR) which was remodeled by a Chinese scholar Richang Zheng in 1999. The scale was divided into four dimensions, such as: 1) making conversations; 2) making friends; 3 ) the ways to get along with people; and 4) interpersonal relationship with heterosexual objects. Each dimension consists of 7 questions, which covers 28 questions at totals.

Then, according to their actual conditions, the respondents fill their answers by dualistic (yes of no) judgments in the questionnaires. If they feel that the descriptions were met their actual situation, they said "yes" by 1 point, otherwise said "no" by 0 point. Finally, the higher the total scores they answered, the more the distress they felt, and vice versa. If the respondents get 0 to 8 points, it means they are totally comfortable or minor distressed from interpersonal contact. If the score is between 9 and 14 points, it means that they are determined as moderately distressed. In the DSIR, 15 to 28 points indicates that they are distressed severely.

\section{Results}

\subsection{Descriptive statement}

This study was randomly selected 581 college students (260 male and 321 female) from poor families in two universities at Weihai, Shandong Province, China. Among them, 542 students are categorized from towns, accounted for $93 \%$ at totals; and 39 students are categorized from cities, accounted for $7 \%$ of total samples. Regarding their social status at schools, $160(27.5 \%)$ respondents are categorized to student leaders, 421 (72.5\%) respondents are categorized to nonstudent leaders. From the aspect of family properties, 85 respondents were detected from only-child families, accounted for $14.6 \%$, and $496(85.4 \%)$ respondents were detected from multichildren families.

We used SPSS 19.0 to analyze final statement and student mental health reports. The questionnaire's Cronbach's alpha was calculated to 0.86 , and its splithalf reliability was calculated to 0.78 . This indicated a good-fit from internal consistency coefficient and validity.

\subsection{The Diagnostic Scale of Interper- sonal Relationship}

The overall situation was detected at the interpersonal disturbance of the college students from poor families. From the scores, it can be seen that the moderate grade of the interpersonal disturbance of college students from poor families makes up $30.6 \%$, and the severe one makes up $9.3 \%$; the total detection rate is $40 \%$ (see Table 1).

From the four dimensions of interpersonal relationships, the different degree of the interpersonal disturbance detected from the college students at poor families can be seen as follows: the disturbance of making friends $>$ the disturbance of communicating with others $>$ the disturbance of interpersonal relationship with 
heterosexual objects $>$ the disturbance of knowing ways to get along with others. This study shows that nearly $60 \%$ of the college students from poor families have good interpersonal relationships; nearly one third of them have moderate grade of interpersonal disturbance, and only less than $10 \%$ suffer it very seriously. And the highest rate of the subjects who suffer interpersonal disturbance reaches $46 \%$. These students have a tendency of emotional instability and psychological unbalance and are often in a contradictory state. However, there are $87 \%$ of the subjects performed well on this dimension, indicating these students respect others, and also have the courage to take responsibility as well as to convince us they have a good adaptability to the environment. With a high morality at sincerity, tolerance and responsibility, they can leave a favorable impression on others.

\section{Discussions and Findings}

From the aforementioned analysis, we have also conducted T-test to detect the difference between male and female as independent variables (see Table2). The result shows that there are significant differences between male and female in three dimensions, such as: 1) their interpersonal relationships; 2) their ways of getting along with other; 3) and making friends with heterosexual objects. When it comes to interpersonal relationships, female are distressed much more than male, but the degrees of male's disturbance are much higher than that of female in the other two aspects, such as: 1) their ways of getting along with other; 2) and making friends with heterosexual objects.

These aforementioned points are also consistent and followed by the conclusions of Liu' study on interpersonal relationships from ordinary college students [4]. Among the subjects, students came from only-child families got much higher scores in the three dimensions than that of multi-children families (see Table 3). The final results were detected significant differences on their interpersonal contacts from college students depended on their gender and family properties.

\section{References}

[1]Xiuqin Chen, "The research and countermeasures of the interpersonal disturbance of college students," Journal of Zhanjiang Normal University, pp.138-140, 2004.

[2] Xuelian Wang, Nengfeng Xu, and Qiaoyu Jiang,"Medical students' interpersonal distress and its relationship with their families," Chinese Journal of Public Health, pp.270-272, 2008.

[3] Tao Wang, Bo Xi, and Cuili Wang, "Analysis of psychological and social factors that influence college students' interpersonal disturbance," Chinese Journal of Public Health, pp.533-534, 2007.

[4] Zhiyuan Liu, "The relationship between gender and interpersonal disturbance of college students," Chinese Health Service Management, pp.9-21, 2009.

[5] Weimin Tang,"Research on characteristics of college students' interpersonal relationships and the influence of the conversion impression on it," Psychology Science, pp.108-109, 2001.

[6] Quancai Li, "Current situation of college students' interpersonal relationships in China," Journal of School Health, pp.47-48, 2002.

[7] Chongyong Sun, "Research on normal university students' interpersonal disturbance," Special Education, pp.8689, 2007. 
Table1: The overall situation of interpersonal disturbance of the college students from poor families.

\begin{tabular}{|c|c|c|c|c|c|c|c|c|c|c|}
\hline \multirow[t]{2}{*}{ Condi. } & \multicolumn{2}{|c|}{ Total scores } & \multicolumn{2}{|c|}{$\begin{array}{l}\text { Making } \\
\text { Conversations }\end{array}$} & \multicolumn{2}{|c|}{ Making Friends } & \multicolumn{2}{|c|}{$\begin{array}{l}\text { Ways to get } \\
\text { along with } \\
\text { people }\end{array}$} & \multicolumn{2}{|c|}{$\begin{array}{l}\text { interpersonal } \\
\text { relationship } \\
\text { with } \\
\text { heterosexual } \\
\text { objects }\end{array}$} \\
\hline & $\mathrm{N}$ & $\%$ & $\mathrm{~N}$ & $\%$ & $\mathrm{~N}$ & $\%$ & $\mathrm{~N}$ & $\%$ & $\mathrm{~N}$ & $\%$ \\
\hline Better & 349 & 60.1 & 370 & 63.7 & 316 & 54.4 & 506 & 87.1 & 396 & 68.2 \\
\hline $\begin{array}{l}\text { Minor } \\
\text { Worse }\end{array}$ & 178 & 30.6 & 193 & 33.2 & 222 & 38.2 & 64 & 11.0 & 143 & 24.6 \\
\hline Worse & 54 & 9.3 & 18 & 3.1 & 43 & 7.4 & 11 & 1.9 & 42 & 7.2 \\
\hline
\end{tabular}

Notes: 1) Better: 0 to 8 points, totally comfortable or minor distressed from interpersonal contact;

2) Minor worse: 9 to 14 points, determined as moderately distressed from interpersonal contact; and 3) Worse: 15 to 28 points, determined as distressed severely from interpersonal contact.

Table2: The T-test of gender of the college students from poor families.

\begin{tabular}{lccccc}
\hline Dimension & \multicolumn{3}{c}{ Male } & \multicolumn{3}{c}{ Female } & $\mathrm{t}$ \\
\hline & Mean & S.D. & Mean & S.D. & \\
\hline Total scores & 7.84 & 5.21 & 7.46 & 5.14 & 0.867 \\
$\begin{array}{l}\text { 1) making } \\
\quad \text { conversations }\end{array}$ & 2.18 & 1.72 & 1.96 & 1.67 & 1.494 \\
$\begin{array}{l}\text { 2) making friends } \\
\text { 3) ways to get } \\
\text { along with }\end{array}$ & 2.33 & 1.79 & 2.72 & 1.91 & $-2.549^{* *}$ \\
$\begin{array}{l}\text { people } \\
\text { 4) Interpersonal } \\
\text { relationship }\end{array}$ & 1.32 & 1.35 & 1.09 & 1.33 & $2.077^{* *}$ \\
$\begin{array}{l}\text { with } \\
\text { heterosexual } \\
\text { objects }\end{array}$ & 2.00 & 1.71 & 1.71 & 1.61 & $2.379^{* *}$ \\
\hline
\end{tabular}

Note: ${ }^{*} \mathrm{P}<0.05,{ }^{* *} \mathrm{P}<0.01$

Table 3: The T-test between only-child families and multi-children families of the college students from poor families.

\begin{tabular}{|c|c|c|c|c|c|}
\hline Dimension & \multicolumn{2}{|c|}{ only-child families } & \multicolumn{2}{|c|}{ multi-children families } & $\mathrm{t}$ \\
\hline & Mean & S.D. & Mean & S.D. & \\
\hline Total scores & 8.97 & 6.44 & 7.40 & 4.89 & $2.607^{*}$ \\
\hline $\begin{array}{l}\text { 1) making } \\
\text { conversations }\end{array}$ & 2.42 & 1.97 & 2.00 & 1.64 & $2.144^{*}$ \\
\hline 2) making friends & 2.66 & 1.92 & 2.53 & 1.86 & 0.587 \\
\hline $\begin{array}{l}\text { 3) ways to get } \\
\text { along with } \\
\text { people }\end{array}$ & 1.79 & 1.88 & 1.09 & 1.20 & $4.511^{* *}$ \\
\hline $\begin{array}{l}\text { 4) Interpersonal } \\
\text { relationship } \\
\text { with } \\
\text { heterosexual } \\
\text { objects }\end{array}$ & 2.10 & 1.87 & 1.78 & 1.61 & 1.663 \\
\hline
\end{tabular}

